\title{
High-throughput 3-dimensional culture of epithelial ovarian cancer cells as preclinical model of disease
}

\author{
Victoria Heredia-Soto ${ }^{1,2}$, Andrés Redondo ${ }^{3,4,5}$, Alberto Berjón ${ }^{1,6}$, María Miguel- \\ Martín ${ }^{1}$, Esther Díaz ${ }^{4}$, Roberto Crespo $^{4}$, Alicia Hernández ${ }^{7}$ Laura Yébenes ${ }^{1,6}$, \\ Alejandro Gallego ${ }^{3}$, Jaime Feliu ${ }^{2,3,4,5,8}$, David Hardisson ${ }^{1,5,6,9}$ and Marta Mendiola ${ }^{1,2,9}$ \\ ${ }^{1}$ Molecular Pathology and Therapeutic Targets Research Lab, Instituto de Investigación del Hospital Universitario La Paz, \\ IdiPAZ, Hospital Universitario La Paz, HULP, Madrid 28046, Spain \\ ${ }^{2}$ Centro de Investigación Biomédica en Red de Cáncer, CIBERONC. Instituto de Salud Carlos III, Madrid 28029, Spain \\ ${ }^{3}$ Department of Medical Oncology, Hospital Universitario La Paz, HULP, Madrid 28046, Spain \\ ${ }^{4}$ Translational Oncology Research Lab, IdiPAZ, Hospital Universitario La Paz, HULP, Madrid 28046, Spain \\ ${ }^{5}$ School of Medicine, Universidad Autónoma de Madrid, UAM, Madrid 28029, Spain \\ ${ }^{6}$ Department of Pathology, Hospital Universitario La Paz, HULP, Madrid 28046, Spain \\ ${ }^{7}$ Department of Gynecology and Obstetrics, Hospital Universitario La Paz, HULP, Madrid 28046, Spain \\ ${ }^{8}$ Cátedra UAM-AMGEN, Universidad Autónoma de Madrid, Campus de Cantoblanco, Madrid 28049, Spain \\ ${ }^{9}$ Molecular Pathology Section, Instituto de Genética Molecular y Médica, INGEMM, Hospital Universitario La Paz, HULP, Madrid \\ 28046, Spain \\ Correspondence to: Marta Mendiola, email: marta.mendiola@idipaz.es \\ David Hardisson, email: david.hardisson@salud.madrid.org \\ Keywords: ovarian cancer; epithelial mesenchymal transition; 3D cell culture model
}

Received: August 18, $2017 \quad$ Accepted: March 19, $2018 \quad$ Published: April 24, 2018

Copyright: Heredia-Soto et al. This is an open-access article distributed under the terms of the Creative Commons Attribution License 3.0 (CC BY 3.0), which permits unrestricted use, distribution, and reproduction in any medium, provided the original author and source are credited.

\section{ABSTRACT}

Background: Recent reports have identified distinct genomic patterns in ovarian carcinoma, including proliferative and mesenchymal-like groups, with worse outcome. The exact mechanisms driving the onset and progression of these tumors are still poorly understood. Additionally, researchers are concerned about the correct subtype stratification of the available cell line models, and the exploration of alternatives to monolayer culture. Identification of biomarkers to stratify cell lines, characterization of important processes as epithelial-mesenchymal transition (EMT), and the use of three-dimensional (3D) cultures as alternative models could be useful for cell line classification.

Methods and Results: In this work, we present a descriptive analysis of 16 commonly used ovarian cancer cell lines. We have studied their morphology in 2and 3D culture, and their response to cisplatin, observing in the majority of them an increased resistance in 3D. We have also performed an immunohistochemical analysis for proliferation marker Ki-67, and EMT related markers to establish phenotypes. Epithelial cells tend to show higher proliferative rates, and mesenchymal cells show an increase in EMT related markers, especially when cultured in 3D conditions.

Conclusions: We have stated the complex heterogeneity of ovarian cancer models, resembling primary tumors, agreeing with the argument that the cell line model for in vitro experiments must be carefully chosen. Our results also support that tridimensional culture could be a very helpful alternative in ovarian cancer research. Regarding EMT, a very important process for the development of this disease, some related biomarkers might be further characterized for their role in this disease development. 


\section{INTRODUCTION}

The vast majority of malignant ovarian cancer cases are carcinomas, presumably originating from the Müllerian epithelium of the ovarian surface and the fallopian tube. The World Health Organization (WHO) classification distinguishes serous, mucinous, endometrioid and clear cell as the main histological subtypes. In the serous category, accounting for over $70 \%$ of all ovarian carcinomas (OC), the existence of two different diseases is now well established, low- and high-grade tumors, with distinct morphological and molecular characteristics [1]. The first step for dissemination involves detachment from the primary tumor and shedding to the abdominal cavity as individual cells or spheroids, both usually present in patients' ascites $[2,3]$. After this initial settlement on the peritoneal mesothelial lining, cells may activate mechanisms to start the metastatic outgrowth.

One of these mechanisms, epithelial to mesenchymal transition (EMT), is a developmental program that transiently disrupts cell-cell adhesion and converts epithelial cells into more migratory and invasive mesenchymal cells [4]. This process and its regulators have also been related to chemoresistance, emphasizing its relevance with respect to recurrence of disease $[5,6]$. Noteworthy, different studies have pointed proliferative and mesenchymal-like groups, based on molecular features, and related them with a worse prognosis $[7,8]$.

The study of relevant pathways for cancer development has been facilitated by cell-based models. Immortalized OC cell lines have been used as an alternative to freshly isolated tumor cells since they have extended lifespan and their clonal nature reduces interexperimental variability. However, when cultured as a twodimensional (2D) monolayer, these cell lines demonstrate low functionality and an altered phenotype compared to primary cultures. There is an urgent need to characterize the existing models in order to use the most suitable ones for research. Additionally, alternatives to the classical monolayer culture such as three-dimensional (3D) cell culture that better represent tumor features, should be considered.

The main objective of this study was to establish 3D OC models, comparing them with bidimensional culture, and to characterize them for their growth, response to treatment, and expression of EMT markers.

\section{RESULTS}

\section{Optimization and characterization of two- dimension and spheroid growth $\mathrm{OC}$ cell lines}

Two-dimensional morphology was analyzed by phase contrast imaging. We found two different patterns: round or epithelial (A2780, A2780CIS, OVCAR3, OAW28, PEA2, PEO23, TO14, PEO14, PEO1, PEO4 and PEO6), and mesenchymal or fibroblast-like (PEA1, PEO16, OV56, SKOV3 and 59M) (Figure 1A). The doubling time ranges from 24 to 58 hours (Table 1), similar to previously reported data for ovarian cancer cell lines [9]. Mean values for epithelial and mesenchymal morphology cell lines are not statistically different (36.56 \pm 10.26 vs $36.21 \pm 8.67$, respectively).

Spheroids individually created per well on ultra low attachment (ULA) plates (Corning) were quite reproducible, as previously described [10]. Using this method, we were able to detect three different patterns for $3 \mathrm{D}$ growth of the cells. Some cell lines adopted a loose aggregate conformation (A2780, A2780CIS, OVCAR3, OAW28, PEA1, PEA2, PEO23, TO14), others had a more compact aggregate structure with an irregular, nonspherical, and a less defined outer perimeter (PEO14, PEO1, PEO4 and PEO6), and a third group of cells, that adopted a tight spheroid structure, with very well defined perimeters under 3D culture (PEO16, OV56, SKOV3 and $59 \mathrm{M}$ ). Interestingly, the four cell lines that form compact spheroids share a mesenchymal or fibroblast-like morphology (Figure 1B).

When cultured in monolayer, OC cell lines do not display any morphological features to indicate histology. However, on 3D, H\&E stain revealed some features, including the presence of papillae in some of them, and existence of acellular central regions due to apoptosis or necrosis, as in tumor tissue (data not shown). Changes in size, measured in bright field microscopy, could be a surrogate marker of cell growth, but only in compact spheroids, so we used Ki-67 staining for evaluation of proliferation, that diminishes with time in compact spheres such as SKOV3, and remains constant in aggregates, as represented by PEO1 (Supplementary Figure 1).

\section{Cisplatin (CDDP) treatment}

Monolayer cultures and spheroids were treated with increasing concentrations of CDDP for $72 \mathrm{~h}$. Dosedependent reduction in cell viability was observed, but differences in drug response in $2 \mathrm{D}$ experiments are independent of histotype, phenotype or spheroid formation categories. Table 1 lists the $\mathrm{IC}_{50}$ values calculated for CDDP in ovarian cancer cell lines spheroids and monolayer cultures. Four groups of cell lines were established according to their $\mathrm{IC}_{50}$ values, taking IOSE cells as a reference $\left(\mathrm{IC}_{50}=2 \mu \mathrm{M}\right)$ : sensible cells $\left(\mathrm{IC}_{50}<\right.$ $3 \mu \mathrm{M}$ ), partially sensitive cells $\left(\mathrm{IC}_{50}\right.$ between 3 and 6 $\mu \mathrm{M})$, resistant cells $\left(\mathrm{IC}_{50}\right.$ between 6 and $\left.12 \mu \mathrm{M}\right)$, and very resistant cells $\left(\mathrm{IC}_{50}>12 \mu \mathrm{M}\right)$.

In all cell lines, independent of their 3D growth pattern, platinum response was evaluated by a luminescent assay (CellTiter-Glo) (Table 1). Additionally, CDDP sensitivity was evaluated by size and CAM staining in the four cell lines that are able to form compact spheroids (PEO16, OV56, SKOV3 
and 59M) obtaining comparable results (Figure 2). In this latter group, two cell lines maintain similar $\mathrm{IC}_{50}$ values (fold change $<2$, PEO16 and 59M) whilst the other two show an increase when cultured in 3D (6.2 and 4.0 fold for OV56 and SKOV3, respectively). The remaining group of aggregate forming cell lines, with the exception of two of them (A2780CIS and OVCAR3), did not reach the $\mathrm{IC}_{50}$ values when cultured on $3 \mathrm{D}$ conditions at the same concentration range set for $2 \mathrm{D}$ experiments (100 $\mu \mathrm{M}$ top concentration), and only one (A2780CIS), experimented a decrease in $\mathrm{IC}_{50}$ (Table 1)

\section{Immunohistochemical analysis}

Ki-67 was employed to evaluate cell proliferation of cultures (Supplementary Figure 1 and Table 1). The percentage of positive cells is similar comparing 2- and 3D globally ( $42.50 \pm 26.39$ vs $47.37 \pm 6.70$, respectively); no statistical differences were observed between $3 \mathrm{D}$ growing

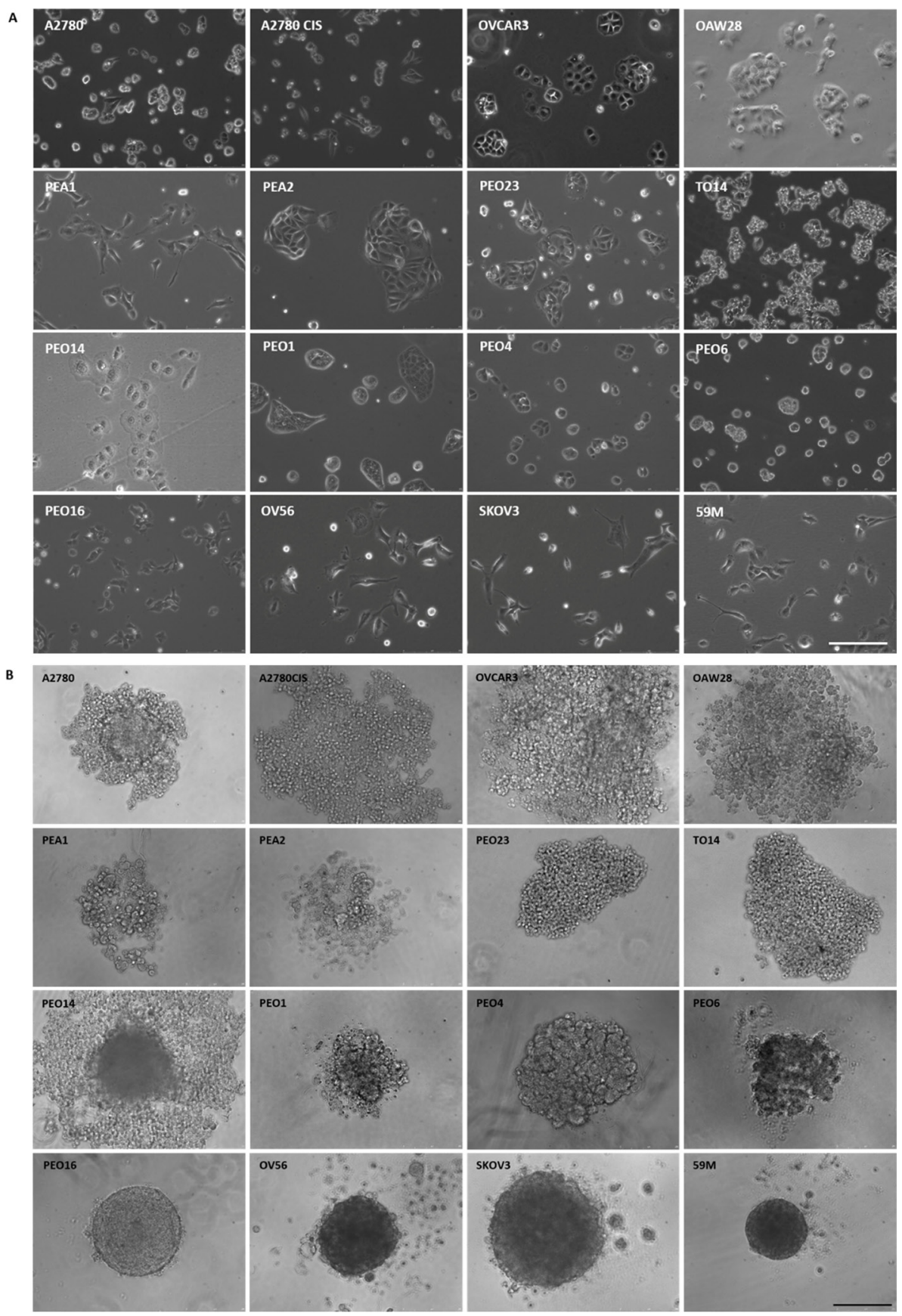

Figure 1: Morphological features of OC cell lines. Phase contrast images. (A) 2D-cultures show epithelial and fibroblast-like phenotypes; (B) 3D-cultured cells after 4 days formed 3 different structures: loose (top 2 rows) or compact (third row) aggregates and tight spheroids (bottom row). Scale bars $=250 \mu \mathrm{m}$. 
Table 1: Main characteristics of ovarian cancer cell lines

\begin{tabular}{|c|c|c|c|c|c|c|c|}
\hline Cell Line & Origin & Morphology & $\begin{array}{c}\text { Spheroid } \\
\text { type }\end{array}$ & $\begin{array}{l}\text { D.T. } 72 \mathrm{~h} \\
\text { (h) }\end{array}$ & $\begin{array}{c}\mathrm{IC}_{50} \pm \mathrm{S} . \mathrm{D} . \\
(\mu \mathrm{M})\end{array}$ & Resist. & $\begin{array}{c}I_{50} \\
(\mu \mathrm{D} \pm \mathrm{M})\end{array}$ \\
\hline A 2780 & $\mathrm{~T}$ & Rounded & LA & 30.72 & $3.51 \pm 0.69$ & PR & NR \\
\hline A2780CIS & $\mathrm{T}$ & Rounded & LA & 31.38 & $13.84 \pm 0.93$ & VR & $0.66 \pm 0.10$ \\
\hline OVCAR3 & A & Rounded & LA & 27.22 & $5.01 \pm 0.28$ & PR & $44.57 \pm 0.71$ \\
\hline PEO1 & A & Rounded & CA & 47.83 & $5.52 \pm 0.42$ & PR & NR \\
\hline PEO4 & A & Rounded & $\mathrm{CA}$ & 33.34 & $16.11 \pm 1.18$ & VR & NR \\
\hline PEO6 & A & Rounded & $\mathrm{CA}$ & 34.27 & $11.94 \pm 2.74$ & VR & NR \\
\hline PEA2 & A & Rounded & LA & 44.13 & $20.80 \pm 0.54$ & VR & NR \\
\hline PEO14 & A & Rounded & $\mathrm{CA}$ & 41.28 & $2.68 \pm 0.11$ & S & NR \\
\hline PEO23 & $\mathrm{A}$ & Rounded & LA & 29.32 & $10.37 \pm 0.30$ & $\mathrm{R}$ & NR \\
\hline TO14 & $\mathrm{T}$ & Rounded & LA & 24.21 & $10.43 \pm 0.55$ & $\mathrm{R}$ & NR \\
\hline OAW28 & A & Rounded & LA & 58.45 & $4.59 \pm 0.61$ & PR & NR \\
\hline PEA1 & A & Spindle & LA & 42.06 & $15.47 \pm 2.31$ & VR & NR \\
\hline PEO16 & A & Spindle & CS & 33.76 & $5.48 \pm 0.06$ & PR & $7.21 \pm 2.06$ \\
\hline OV56 & A & Spindle & $\mathrm{CS}$ & 24.46 & $1.51 \pm 0.22$ & $\mathrm{~S}$ & $9.34 \pm 3.66$ \\
\hline SKOV3 & A & Spindle & $\mathrm{CS}$ & 33.77 & $11.50 \pm 1.47$ & $\mathrm{R}$ & $46.03 \pm 9.50$ \\
\hline $59 \mathrm{M}$ & A & Spindle & CS & 47 & $9.47 \pm 0.78$ & $\mathrm{R}$ & $11.83 \pm 0.55$ \\
\hline
\end{tabular}

Origin: $\mathrm{T}=$ Tumor, $\mathrm{A}=$ Ascites; Spheroid morphology: $\mathrm{LA}=$ loose aggregate, $\mathrm{CA}=$ compact aggregate, $\mathrm{CS}=$ compact spheroid; D.T. $72 \mathrm{~h}=$ doubling time at $72 \mathrm{~h}$; S.D. = Standard Deviation; Resistance grade: $\mathrm{S}=$ sensitive, $\mathrm{PR}=$ partially resistant, $\mathrm{R}=$ resistant, $\mathrm{VR}=$ very resistant; $\mathrm{NR}=$ not reached.

patterns, although the less proliferative seemed to be the compact aggregate type ( $52.5 \pm 18.08$ for loose aggregates, $18.75 \pm 5.15$ for compact aggregates, and $59.12 \pm 20.24$ for compact spheroids). Mean values became statistically different when we clustered the cells by morphological groups, increasing on 3D for the rounded cells (36.36 \pm 28.64 vs $61.00 \pm 36.49, p<0.05)$, and decreasing for spindle subtype $(56.00 \pm 15.16$ vs $17.40 \pm 9.24, p<0.05)$.

Supplementary Table 1 includes detailed information regarding reported molecular alterations and putative histotype of the cell lines included in this study. We have found some discrepancies regarding P53 expression. When it is completely absent or very highly expressed, it is widely used as a surrogate marker for TP53 mutation, a ubiquitous molecular sign in high-grade serous ovarian carcinoma (HGSOC) [11]. Twelve of the cell lines showed abnormal expression of P53. The remaining cell lines, OVCAR3, OAW28, PEO14 and PEO23, presenting a normal expression pattern of the protein in our study, have been reported as TP53 mutated by different authors. PEO16, A2780 and 2780CIS showed an abnormal staining pattern; however, they are not reported as mutated on previous studies.

Table 2 summarizes the results of the inmunohistochemistry (IHC) study on EMT-related markers. For the phenotypical classification of cell lines, we used the epithelial markers E-Cadherin (ECAD) and Pan-Cytokeratin (PANCK), and the mesenchymal markers $\mathrm{N}$-Cadherin (NCAD) and Vimentin (VIM). Expression of these 4 markers was not mutually exclusive in the panel analyzed. With this algorithm, we classified four cell lines as purely epithelial (PEO4, PEO6, OAW28 y OVCAR3), and five as purely mesenchymal (PEO23, TO14, PEO16, A2780 y A2780CIS); the remaining cell lines were classified as intermediate. This phenotypical classification correlates with the morphology exhibited by the cells when cultured in monolayer in 12 of the lines; the remaining cell lines (PEO23, TO14, A2780 and A2780CIS) exhibited a rounded morphology but expressed a mesenchymal immunohistotype. Interestingly, none of the compact aggregates expressed NCAD, and none of the cells forming compact spheroids expressed ECAD, and the latter remain in the mesenchymal category by this IHC classification (Supplementary Figure 2). Pooling pure and intermediate subtypes for statistical analysis, mesenchymal cells had a significant reduction on their doubling time compared to the epithelial group $(41.07 \pm 9.68$ vs $31.83 \pm 7.15, p=0.04)$; no significant differences were observed on Ki-67 expression between 2- or 3D culture (data not shown). 
We also assessed the expression of master regulators of the EMT process in 2- and 3D culture conditions by IHC (Table 2). From the 16 cell lines analyzed on flat culture, markers were expressed as follows: Seven (44\%) are positive for SNAIL, $2(12 \%)$ are positive for SLUG and ZEB2, 3 (19\%) for ZEB1, 9 (56\%) for TWIST1, and $13(81 \%)$ for TWIST2. The expression is variable and we did not find any relation with the $3 \mathrm{D}$ growth patterns as aggregate or compact spheroids, response to platinum or proliferation, and the expression of the analyzed
A
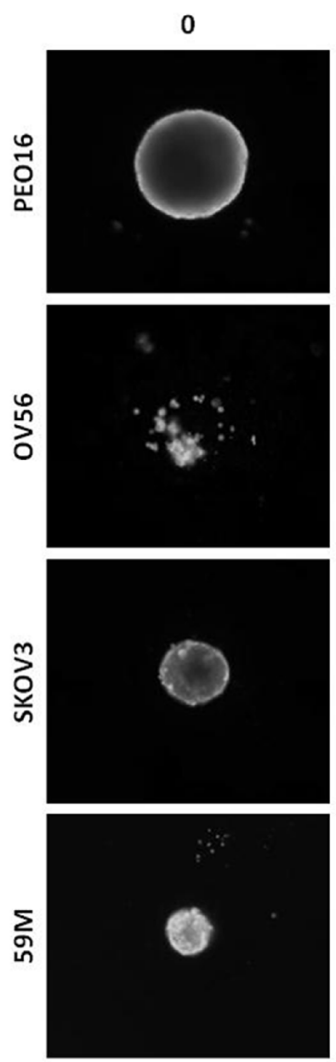

B

\section{$\operatorname{CDDP}(\mu \mathrm{M})$}
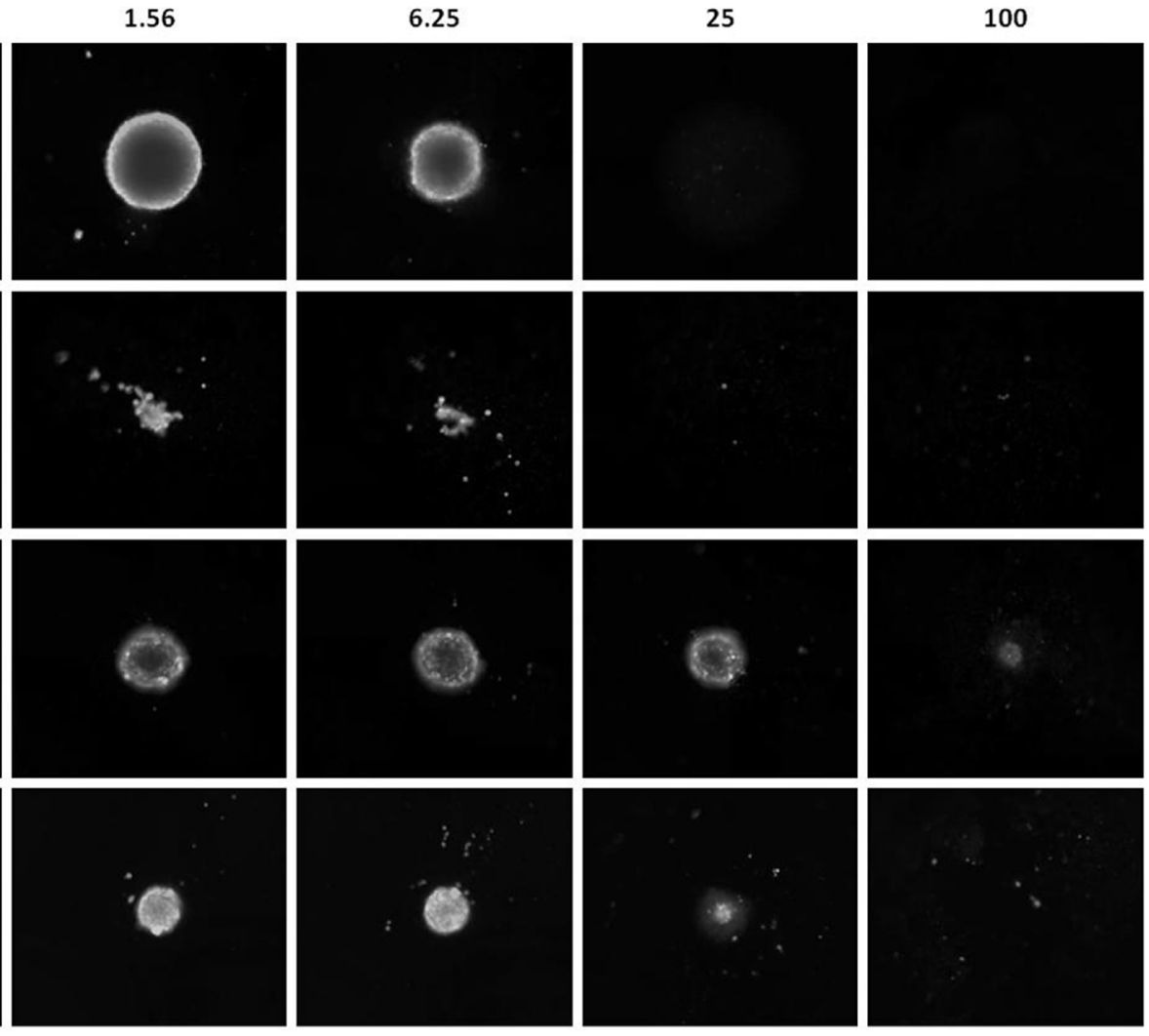

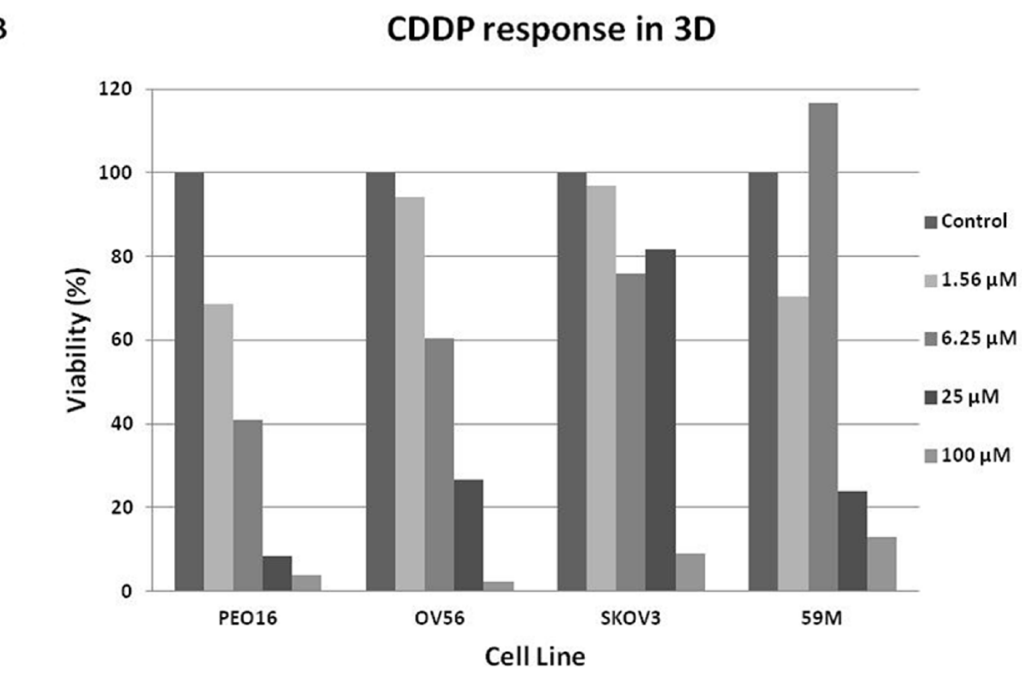

Figure 2: Dose-dependent sensitivity of Spheroids from 4 of the cell lines analyzed, with compact morphology. (A) CAM stained spheroids. Cells were treated with different CDDP concentrations. Images obtained with Celigo S cytometer; (B) Quantification of cell viability of the cells at different CDDP concentrations calculated with mean integrated CAM intensity values. 
Table 2: IHC of EMT biomarkers expression in cell lines, both in monolayer (2D) and 3D culture

\begin{tabular}{|c|c|c|c|c|c|c|c|c|c|c|c|c|c|c|c|c|c|c|c|c|c|c|}
\hline \multirow{3}{*}{ Cell Line } & \multicolumn{12}{|c|}{ EMT Markers } & \multicolumn{10}{|c|}{ Phenotype Classification } \\
\hline & \multicolumn{2}{|c|}{ SNAIL } & \multicolumn{2}{|c|}{ SLUG } & \multicolumn{2}{|c|}{ ZEB1 } & \multicolumn{2}{|c|}{ ZEB2 } & \multicolumn{2}{|c|}{ TWIST1 } & \multicolumn{2}{|c|}{ TWIST2 } & \multicolumn{2}{|c|}{ ECAD } & \multicolumn{2}{|c|}{ PANCK } & \multicolumn{2}{|c|}{ NCAD } & \multicolumn{2}{|c|}{ VIM } & \multicolumn{2}{|c|}{ Phenotype } \\
\hline & 2D & 3D & 2D & 3D & 2D & 3D & 2D & 3D & 2D & 3D & 2D & 3D & 2D & 3D & 2D & 3D & 2D & 3D & 2D & 3D & 2D & 3D \\
\hline PEO4 & - & - & - & - & - & - & + & - & + & ++ & + & + & $\mathrm{R}$ & $\mathrm{C}$ & $\mathrm{C}$ & $\mathrm{C}$ & $\mathrm{A}$ & $\mathrm{A}$ & $\mathrm{A}$ & A & E & $\mathrm{E}$ \\
\hline PEO6 & - & + & - & + & - & - & - & - & + & ++ & - & + & $\mathrm{R}$ & $\mathrm{R}$ & $\mathrm{C}$ & $\mathrm{C}$ & A & A & A & A & E & $\mathrm{E}$ \\
\hline OAW28 & + & + & - & - & - & - & - & - & - & ++ & + & + & $\mathrm{R}$ & $\mathrm{R}$ & $\mathrm{C}$ & $\mathrm{C}$ & A & $\mathrm{A}$ & A & $\mathrm{A}$ & $\mathrm{E}$ & E \\
\hline OVCAR3 & + & + & - & - & - & - & - & - & + & ++ & + & + & $\mathrm{R}$ & $\mathrm{R}$ & $\mathrm{C}$ & $\mathrm{C}$ & A & A & A & $\mathrm{A}$ & $\mathrm{E}$ & $\mathrm{E}$ \\
\hline PEA2 & - & - & - & + & - & - & - & + & + & + & + & ++ & $\mathrm{R}$ & $\mathrm{C}$ & $\mathrm{C}$ & $\mathrm{C}$ & $\mathrm{A}$ & $\mathrm{A}$ & $\mathrm{R}$ & $\mathrm{R}$ & IE & IE \\
\hline PEO1 & - & - & - & + & - & - & - & + & + & + & + & + & $\mathrm{R}$ & $\mathrm{R}$ & $\mathrm{C}$ & $\mathrm{C}$ & A & $\mathrm{A}$ & $\mathrm{R}$ & $\mathrm{R}$ & IE & IE \\
\hline PEO14 & + & + & - & + & - & + & - & - & - & ++ & + & + & $\mathrm{R}$ & $\mathrm{R}$ & $\mathrm{C}$ & $\mathrm{R}$ & A & $\mathrm{R}$ & $\mathrm{R}$ & $\mathrm{R}$ & IE & I \\
\hline PEA1 & - & + & - & + & - & + & - & + & - & ++ & + & ++ & A & A & $\mathrm{C}$ & $\mathrm{R}$ & $\mathrm{A}$ & $\mathrm{A}$ & $\mathrm{C}$ & $\mathrm{C}$ & I & $\mathrm{IM}$ \\
\hline OV56 & + & + & - & + & - & + & + & + & - & ++ & + & + & A & $\mathrm{A}$ & $\mathrm{R}$ & $\mathrm{C}$ & $\mathrm{R}$ & $\mathrm{R}$ & $\mathrm{C}$ & $\mathrm{C}$ & IM & IM \\
\hline SKOV3 & - & + & - & + & + & + & - & - & - & + & + & + & A & A & $\mathrm{C}$ & $\mathrm{R}$ & $\mathrm{R}$ & $\mathrm{R}$ & $\mathrm{C}$ & $\mathrm{C}$ & $\mathrm{IM}$ & IM \\
\hline $59 M$ & + & - & - & - & - & + & - & - & + & ++ & - & - & A & A & $\mathrm{C}$ & $\mathrm{R}$ & $\mathrm{C}$ & $\mathrm{C}$ & $\mathrm{C}$ & $\mathrm{C}$ & IM & IM \\
\hline PEO23 & - & + & - & + & + & + & - & + & - & ++ & + & ++ & A & $\mathrm{A}$ & A & A & A & A & $\mathrm{C}$ & $\mathrm{C}$ & M & M \\
\hline TO14 & - & + & - & - & + & - & - & + & - & ++ & + & ++ & $\mathrm{A}$ & A & $\mathrm{A}$ & $\mathrm{A}$ & A & A & $\mathrm{C}$ & $\mathrm{C}$ & M & M \\
\hline PEO16 & - & - & - & - & - & + & - & + & + & ++ & + & - & A & $\mathrm{A}$ & $\mathrm{A}$ & $\mathrm{A}$ & $\mathrm{C}$ & $\mathrm{C}$ & $\mathrm{C}$ & $\mathrm{R}$ & M & M \\
\hline A2780 & + & + & + & - & - & + & - & + & + & ++ & - & + & A & $\mathrm{A}$ & $\mathrm{A}$ & $\mathrm{A}$ & $\mathrm{R}$ & $\mathrm{R}$ & $\mathrm{C}$ & $\mathrm{C}$ & M & M \\
\hline A2780CIS & + & + & + & - & - & + & - & + & + & ++ & + & + & A & A & A & A & $\mathrm{R}$ & $\mathrm{R}$ & $\mathrm{C}$ & $\mathrm{C}$ & $\mathrm{M}$ & M \\
\hline
\end{tabular}

Phenotype: $\mathrm{E}=$ epithelial, $\mathrm{IE}=$ intermediate epithelial, $\mathrm{I}=$ intermediate, $\mathrm{IM}=$ intermediate mesenchymal, $\mathrm{M}=$ mesenchymal; $\mathrm{A}=$ absent, $\mathrm{C}=$ conserved, $\mathrm{R}=$ reduced, $+=$ positive (moderate expression), $++=$ positive (high expression), $-=$ negative.

markers. Globally, there is an increased expression of all the EMT markers analyzed in 3D. Specifically, splitting cells according to the epithelial or mesenchymal IHC phenotype, and comparing 2- and 3D culture, we observed an increased expression of SLUG and TWIST markers in the epithelial group and more expression of ZEB1, ZEB2, TWIST1 and TWIST2 in the mesenchymal type, when grown under low attachment conditions.

\section{DISCUSSION}

OC is traditionally divided into five main histological subtypes: serous (low- and high-grade), endometrioid, clear cell and mucinous. HGSOC accounts for more than $70 \%$ of cases, and is responsible for the majority of ovarian cancer related deaths [12]. Recently, large scale molecular profiles have confirmed the existence of different molecular subtypes in HGSOC (proliferative and mesenchymal-like), indicating that ovarian cancer is an heterogeneous disease, with different prognosis [7, 13].

Established cell lines are the most common model in cancer research, and their use has contributed to the understanding of cancer biology in the last decades, but they also have limitations. It is now widely accepted that some of the most frequently used ovarian cancer cell lines, including A2780, SKOV3 and OVCAR3, do not seem to be the most suitable models for the study of HGSOC [14-16].

We agree with other authors that the optimal cell line for in vitro studies must be carefully chosen, depending on numerous factors, including the endpoint of the study, growth characteristics, or histological or genomic background $[10,17]$.

2D culture is easy to handle and highly reproducible, but an objection to this model is that it does not totally mimic some properties of tumors, and sometimes fails to reproduce in vivo drug efficacy. More recently, 3D cell culture models, expected to bridge the gap between 2D and animal models, are becoming more widely used in scientific research, including drug screening and new compounds development fields. Ovarian cancer has common tumor growth characteristics, such as a hypoxic environment, absent in traditional culture models. However, it also has some unique features, such as peritoneal spread as individual cells or aggregates. For all these reasons, 3D unattached culture could be a more representative model for these tumors. 
Previous work has been published on ovarian cancer spheroids culture using different methods [18-21]. However, these models that overcome some of the limitations of 2D, as the architectural growth of the tumor, are not yet fully attained. Reproducibility and easy management in the $2 \mathrm{D}$ setting are more complicated to perform on $3 \mathrm{D}$.

In this study, we characterized ovarian cancer spheroids from 16 commonly used cell lines, using ULA plates, in a highly uniform way, as previously described [10]. This method emulates more precisely the growth as aggregates (loose or compact) but also as solid tumors (compact spheroid), depending on the cell line. Interestingly, in this panel all cell lines with mesenchymal morphology formed compact spheroids. The compactation level on $3 \mathrm{D}$ had also been previously correlated to the spindle cell morphology by other authors [22].

Regarding compact spheroids experiments, assessment of cell number and days of incubation is crucial. An estimated diameter of $400 \mu \mathrm{m}$ could be optimal to mimic the diffusion state in the tumor, which is about $100 \mu \mathrm{m}$ in depth for nutrients and oxygen, and 14 days as final time point was also effective to avoid excessive necrotic areas [23-25]. Proliferation of cells within the compact spheroids decreased over time but this effect is not necessarily accompanied by a decrease in the spheroid volume, which can remain tight and intact but with no viable cells. Therefore, vital staining with CAM could be used as direct indicator of cellular health, and it can also be coupled to Hoechst and PI for a more precise analysis on spheroids viability $[26,27]$.

Differences in cellular response to platinum were determined to be cell line specific. This can be explained because every cell line was established at a different treatment time-points: before or after first line, on different relapse states, or even after alternative chemotherapy regimes. In this study, 2- and $3 \mathrm{D}$ comparison in the compact spheroids group, show two cell lines that retain similar $\mathrm{IC}_{50}$ values, and other two that experiment an increase. The same behavior was seen for the aggregate 3D group where, with the exception of one cell line, all had an increase in the $\mathrm{IC}_{50}$ values. Moreover, most of them do not even reach this value under the same CDDP concentration range tested on $2 \mathrm{D}$. These results are in agreement with the reported by other authors, supporting that cells tend to be more resistant to treatment when growing on 3D [28]. In advanced ovarian cancer, a high percentage of patients will develop ascites, and most of them will finally relapse, experiencing an increase in platinum resistance with recurrence. Under this scenario, and taking into account our results regarding the increased resistance observed in 3D culture, it could be worth considering unattached growth not only for compact spheroids but also for aggregates, to characterize resistance mechanisms in OC, as suggested by other authors [29]. The combination of a very reproducible approach for 3D culture, with reproducible single spheroids or aggregates per well, combined with a semi-automated quantification system as Celigo, could be a suitable model for ovarian cancer resistance research. This methodology allows the measurement of different culture features other than growth, such as migration, invasion or cell cycle progression, turning it into a very attractive approach [27, 30-32].

P53 pathway is disrupted in the majority of human cancers, mainly through mutation or deletion of TP53 itself, and these situations have been associated with poor prognosis and chemoresistance in different types of tumors [33, 34]. In ovarian cancer, P53 is a useful marker to distinguish between HGSOC, mutated in $96 \%$ of the cases [35], and low-grade serous ovarian carcinoma (LGSOC), were mutations are very rare $[1,36]$. In this study, we have detected an abnormal expression of P53 by immunohistochemical analysis in 12 out of 16 cell lines, which has been suggested to be a surrogate marker for TP53 mutation status [37]. However, we found discordant results in other 4 cell lines regarding their reported mutations on literature. These results are in agreement with the observation that P53 IHC accuracy is not perfect, and a combination of different markers might be used in order to better classify available cell lines [15, 17, 38].

We have also evaluated Ki-67 proliferation activity, which revealed a similar proliferation rate in $2-$ and $3 \mathrm{D}$ culture, although it has been shown to decrease in other reports [39]. Interestingly, if we split the sample by morphology, rounded cells increase their proliferation on 3D meanwhile the spindle ones decrease it.

During ovarian cancer progression, both EMT and the reverse process, mesenchymal-epithelial transition (MET) occur in a dynamic way, and a related phenotype has been pointed to have a more aggressive behavior $[35,40]$. We have analyzed a selected panel of EMT markers, and we have observed co-expression of epithelial and mesenchymal markers, supporting the complexity and the dynamism of the process. This plasticity has been previously reported in ovarian cancer, particularly in HGSOC, were the balance between the epithelial and mesenchymal phenotypes is complex [4]. We also observed co-expression of different EMT regulators, grouped differently depending on the phenotypic background but we were not able to discriminate CDDP response rates regarding mesenchymal or epithelial features, probably because EMT is not the only process implicated in resistance mechanisms to platinum therapy, as previously reported [41]. Another explanation could be that we have only used a discrete set of EMT regulators, supported by the fact that the Cancer Genome Atlas Research Network pointed the mesenchymal subtype as one of the groups with a worse outcome. More research in the field should be done to identify related biomarkers $[35,40]$.

In most cell lines, there is an increased expression of master EMT regulators in 3D models comparing with 2D. Other authors have described changes in EMT regulators 
between 2 and 3D ovarian cancer models and this could be in agreement with the role of the EMT process in disease dissemination, when the cells are growing unattached, like the ascitic cells in the abdominal cavity, before seeding the peritoneum [42]. Therefore, 3D culture could be a more suitable model for the study of EMT and related processes to further characterize the role of this mechanism in OC, and to identify additional biomarkers of aggressiveness.

\section{MATERIALS AND METHODS}

\section{2- and 3D culture conditions}

Ovarian cancer cell lines were obtained from the European Collection of Authenticated Cell Cultures (ECACC), and cultured based on the guidelines of the repository. Cells were regularly tested for mycoplasma infection and discontinued after 15 consecutive passages. Some of these lines were established from the same patient during the course of disease, and had received different treatment schemes prior to their establishment: PEA1/ PEA2, PEO1/PEO4/PEO6 and PEO14/PEO23/T014 [43]. The cells were maintained in Roswell Park Memorial Institute (RPMI) or Dulbecco's Modified Eagle Medium (DMEM) (Lonza, Basel, Switzerland) supplemented with $10 \%$ Fetal Bovine Serum (FBS) and $100 \mathrm{U} / \mathrm{ml}$ penicillinstreptomycin (Sigma-Aldrich, MO, USA). Immortalized Ovarian Surface Epithelium (IOSE) cells were obtained from the Canadian OvCaRe Cell Bank and grown in a combination of 199 and MCDB105 (1:1) media (SigmaAldrich) with 5\% FBS and $50 \mu \mathrm{g} / \mathrm{ml}$ gentamicin. All cells were incubated at $37^{\circ} \mathrm{C}$ in a $5 \% \mathrm{CO}_{2}$ incubator. Spheroids were cultured using ULA plates (Corning, NY, USA) as previously described [10], for up to 14 days.

\section{Cell proliferation}

For monolayer experiments, cells were seeded at a density of $6 \times 10^{3}$ cells per well in 96-well plates (MW96). Cellular confluence was measured at different time points $(0,24,48,72$ and 96 h). For 3D experiments, cells were seed at a variable density, set before for each cell line (from 500 to 10000 cells per well) in ULA plates. Growth was tracked measuring spheroid diameter at days 4, 7, 10 and 14. Image acquisition and analysis were performed with Celigo S plate cytometer (Nexcelom, MA, USA).

\section{CDDP effects on ovarian cancer cell lines}

Monolayer culture experiments were carried out in a similar way as proliferation assays and 24 hours after seeding, cells were exposed to different concentrations of (CDDP) for $72 \mathrm{~h}$. After this time, cellular confluence was measured with Celigo $\mathrm{S}$ and $\mathrm{IC}_{50}$ values were calculated using linear regression with GraphPad Prism 7 software (GraphPad Software, CA, USA).
For 3D experiments, after 4 days of culture, spheroids were exposed to CDDP for $72 \mathrm{~h}$. Cell viability was measured using CellTiter-Glo Luminescent assay (Promega, WI, USA). Additionally, in compact spheroids, cells were treated with a fluorescent staining solution containing calcein-AM (CAM) (BD Biosciences) to detect live cells, propidium iodide (PI) (Sigma-Aldrich) for dead cells and Hoechst 33342 (Sigma-Aldrich) to counterstain all nuclei. Mean CAM intensity values obtained by Celigo analysis were used to calculate $\mathrm{IC}_{50}$ by using linear regression.

\section{Histological and immunohistochemical analysis}

Histological studies were performed both in cell pellets from monolayer cultures and aggregates or spheroids. Cell pellets were collected, fixed with 70\% ethanol for $24 \mathrm{~h}$, and paraffin embedded. Spheroids were fixed in $4 \%$ paraformaldehyde solution, embedded in $4 \%$ noble agar (Sigma-Aldrich) and then paraffin embedded. Sections were stained with haematoxylin and eosin (H\&E).

We performed IHC for the markers described below. Briefly, four- $\mu \mathrm{m}$ sections were cut with a semiautomatic microtome HM3508 (MICROM), deparaffinized and rehydrated in water. Antigen retrieval was performed in a DAKO PT Link (Glostrup, Denmark). Peroxidase activity was blocked with Dako Protein block for 10 minutes (containing $0.25 \%$ casein in PBS), then incubated for 30 minutes with primary antibodies, detected with Dako Envision Plus kit, and counterstained with haematoxylin. Antibodies used include: Ki-67 (\#IS626), P53 (\#IS616), ECAD (\#IR059), PANCK (\#IR053), VIM (\#IR630), all from Dako; NCAD (\#ab1221), Snail (\#ab135708), Slug (\#ab38551), Zeb1 (\#ab180905), Twist (\#ab50581), and Twist2 (\#ab57997), all from Abcam (Cambridge, UK), and Zeb2 (\#sc-48789) from Santa Cruz (TX, USA).

Evaluation of immunohistochemical stains was performed as follows: ECAD, NCAD, PANCK, and VIM membrane staining was evaluated as conserved (C), reduced $(\mathrm{R})$ or absent $(\mathrm{A})$; cytoplasmic immunostaining of Snail, Slug, Twist1 and Twist2, and nuclear expression of Zeb1 and Zeb2, was evaluated as positive (moderate or high, when there is possibility of discriminate categories) or negative. P53 and Ki-67 were analyzed as a percentage, for ki-67 as continuous value of positive stained nuclei, and for P53 as two categories: aberrant expression (less than $10 \%$ or more than $60 \%$ positive nuclei), and normal expression (ranging from $11 \%$ to $59 \%$ ), as previously described [33, 44, 45].

Phenotypical classification of the cell lines was done according to the expression of epithelial (ECAD/ PANCK) and mesenchymal (VIM/NCAD) markers. Cells were classified as purely epithelial or mesenchymal when they only expressed epithelial or mesenchymal markers; intermediate phenotypes were established when coexpression of both groups of markers was observed. 


\section{Statistical analysis}

Results are representative of at least three independent experiments in triplicate to sextuplicate, and are represented as mean \pm standard deviation (SD), except 3D experiments which were performed once with 6 replicates for each condition. Chi-Square test and Fischer's exact test (2-sided) were performed for comparisons, and these were considered significant when $p$-values $<0.05$. Graphs and statistical analysis were performed using Microsoft Office Excel (Microsoft, WA, USA), SPSS version 15.0 (IBM Corporation, NY, USA), and GraphPad Prism 7 (GraphPad Software).

\section{CONCLUSIONS}

Spheroids show different features compared with 2D culture. Particularly in OC, epithelial ovarian cancer cells growing as spheroids are frequently detected in the ascites of the patients. We have successfully used a reproducible technique to obtain uniform ovarian cancer spheroids over 16 established cell lines, and characterized their growth, proliferation, and drug response. Compelling evidence has suggested the critical role of EMT in cancer development and progression, but their regulation mechanisms need to be further characterized. We propose the use of 3D models for this purpose that, with optimal instrumentation and computational coupled resources, could represent a promising model for high throughput studies.

\section{Author contributions}

Study conception and design was performed by VHS, AR, JF, DH and MM. Technical assistance was supported by MMM, ED and RC. VHS, AR, AB, AH, LY and AG participated in data collection, analysis, and interpretation of results. The manuscript draft was initially written by VHS, AR, DH and MM, and critically revised by DH and MM.

\section{CONFLICTS OF INTEREST}

The authors declare no potential conflicts of interest related to this work.

\section{FUNDING}

This work was funded by Instituto de Salud Carlos III (ISCIII) and Fondo Europeo de Desarrollo Regional (FEDER), as part of PN I+D+I 2008-2011 Program (\#PI10/630) and Fundación Mutua Madrileña Funding Program. VHS was supported by a $\mathrm{phD}$ fellowship program (\#FI11/00538, ISCIII) and CIBERONC CB16/12/00398.

\section{REFERENCES}

1. Kurman RJ, Shih IM. The Dualistic Model of Ovarian Carcinogenesis: Revisited, Revised, and Expanded. Am J Pathol. 2016; 186:733-47.

2. Naora H, Montell DJ. Ovarian cancer metastasis: integrating insights from disparate model organisms. Nat Rev Cancer. $2005 ; 5: 355-66$.

3. Allen HJ, Porter C, Gamarra M, Piver MS, Johnson EA. Isolation and morphologic characterization of human ovarian carcinoma cell clusters present in effusions. Exp Cell Biol. 1987; 55:194-208.

4. Kalluri R, Weinberg RA. The basics of epithelialmesenchymal transition. J Clin Invest. 2009; 119:1420-28.

5. Davidson B, Tropé CG, Reich R. Epithelial-mesenchymal transition in ovarian carcinoma. Front Oncol. 2012; 2:33.

6. Haslehurst AM, Koti M, Dharsee M, Nuin P, Evans K, Geraci J, Childs T, Chen J, Li J, Weberpals J, Davey S, Squire J, Park PC, Feilotter H. EMT transcription factors snail and slug directly contribute to cisplatin resistance in ovarian cancer. BMC Cancer. 2012; 12:91.

7. Konecny GE, Wang C, Hamidi H, Winterhoff B, Kalli KR, Dering J, Ginther C, Chen HW, Dowdy S, Cliby W, Gostout B, Podratz KC, Keeney G, et al. Prognostic and therapeutic relevance of molecular subtypes in high-grade serous ovarian cancer. J Natl Cancer Inst. 2014; 106:dju249.

8. Wang C, Armasu SM, Kalli KR, Maurer MJ, Heinzen EP, Keeney GL, Cliby WA, Oberg AL, Kaufmann SH, Goode EL. Pooled Clustering of High-Grade Serous Ovarian Cancer Gene Expression Leads to Novel Consensus Subtypes Associated with Survival and Surgical Outcomes. Clin Cancer Res. 2017; 23:4077-85.

9. Létourneau IJ, Quinn MC, Wang LL, Portelance L, Caceres KY, Cyr L, Delvoye N, Meunier L, de Ladurantaye M, Shen Z, Arcand SL, Tonin PN, Provencher DM, Mes-Masson AM. Derivation and characterization of matched cell lines from primary and recurrent serous ovarian cancer. BMC Cancer. 2012; 12:379.

10. Vinci M, Gowan S, Boxall F, Patterson L, Zimmermann M, Court W, Lomas C, Mendiola M, Hardisson D, Eccles SA. Advances in establishment and analysis of three-dimensional tumor spheroid-based functional assays for target validation and drug evaluation. BMC Biol. 2012; 10:29.

11. Köbel M, Rahimi K, Rambau PF, Naugler C, Le Page C, Meunier L, de Ladurantaye M, Lee S, Leung S, Goode EL, Ramus SJ, Carlson JW, Li X, et al. An Immunohistochemical Algorithm for Ovarian Carcinoma Typing. Int J Gynecol Pathol. 2016; 35:430-41.

12. Bowtell DD. The genesis and evolution of high-grade serous ovarian cancer. Nat Rev Cancer. 2010; 10:803-08.

13. Vaughan S, Coward JI, Bast RC Jr, Berchuck A, Berek JS, Brenton JD, Coukos G, Crum CC, Drapkin R, Etemadmoghadam D, Friedlander M, Gabra H, Kaye SB, 
et al. Rethinking ovarian cancer: recommendations for improving outcomes. Nat Rev Cancer. 2011; 11:719-25.

14. Berns EM, Bowtell DD. The changing view of high-grade serous ovarian cancer. Cancer Res. 2012; 72:2701-04.

15. Domcke S, Sinha R, Levine DA, Sander C, Schultz N. Evaluating cell lines as tumour models by comparison of genomic profiles. Nat Commun. 2013; 4:2126.

16. Anglesio MS, Wiegand KC, Melnyk N, Chow C, Salamanca C, Prentice LM, Senz J, Yang W, Spillman MA, Cochrane DR, Shumansky K, Shah SP, Kalloger SE, Huntsman DG. Type-specific cell line models for type-specific ovarian cancer research. PLoS One. 2013; 8:e72162.

17. Barretina J, Caponigro G, Stransky N, Venkatesan K, Margolin AA, Kim S, Wilson CJ, Lehár J, Kryukov GV, Sonkin D, Reddy A, Liu M, Murray L, et al. The Cancer Cell Line Encyclopedia enables predictive modelling of anticancer drug sensitivity. Nature. 2012; 483:603-07.

18. Dong Y, Stephens C, Walpole C, Swedberg JE, Boyle GM, Parsons PG, McGuckin MA, Harris JM, Clements JA. Paclitaxel resistance and multicellular spheroid formation are induced by kallikrein-related peptidase 4 in serous ovarian cancer cells in an ascites mimicking microenvironment. PLoS One. 2013; 8:e57056.

19. Loessner D, Stok KS, Lutolf MP, Hutmacher DW, Clements JA, Rizzi SC. Bioengineered 3D platform to explore cellECM interactions and drug resistance of epithelial ovarian cancer cells. Biomaterials. 2010; 31:8494-506.

20. Chen J, Wang J, Chen D, Yang J, Yang C, Zhang Y, Zhang H, Dou J. Evaluation of characteristics of CD44+CD117+ ovarian cancer stem cells in three dimensional basement membrane extract scaffold versus two dimensional monocultures. BMC Cell Biol. 2013; 14:7.

21. Lee JM, Mhawech-Fauceglia P, Lee N, Parsanian LC, Lin YG, Gayther SA, Lawrenson K. A three-dimensional microenvironment alters protein expression and chemosensitivity of epithelial ovarian cancer cells in vitro. Lab Invest. 2013; 93:528-42.

22. Sodek KL, Ringuette MJ, Brown TJ. Compact spheroid formation by ovarian cancer cells is associated with contractile behavior and an invasive phenotype. Int J Cancer. 2009; 124:2060-70.

23. Asthana A, Kisaalita WS. Microtissue size and hypoxia in HTS with 3D cultures. Drug Discov Today. 2012; 17:810-17.

24. Olive PL, Vikse C, Trotter MJ. Measurement of oxygen diffusion distance in tumor cubes using a fluorescent hypoxia probe. Int J Radiat Oncol Biol Phys. 1992; 22:397-402.

25. Curcio E, Salerno S, Barbieri G, De Bartolo L, Drioli E, Bader A. Mass transfer and metabolic reactions in hepatocyte spheroids cultured in rotating wall gaspermeable membrane system. Biomaterials. 2007; 28:5487-97.
26. Gaskell H, Sharma P, Colley HE, Murdoch C, Williams DP, Webb SD. Characterization of a functional C3A liver spheroid model. Toxicol Res (Camb). 2016; 5:1053-65.

27. Kessel S, Cribbes S, Déry O, Kuksin D, Sincoff E, Qiu J, Chan LL. High-Throughput 3D Tumor Spheroid Screening Method for Cancer Drug Discovery Using Celigo Image Cytometry. SLAS Technol. 2017; 22:454-65.

28. Niero EL, Rocha-Sales B, Lauand C, Cortez BA, de Souza MM, Rezende-Teixeira P, Urabayashi MS, Martens AA, Neves JH, Machado-Santelli GM. The multiple facets of drug resistance: one history, different approaches. J Exp Clin Cancer Res. 2014; 33:37.

29. Alkema NG, Wisman GB, van der Zee AG, van Vugt MA, de Jong S. Studying platinum sensitivity and resistance in high-grade serous ovarian cancer: different models for different questions. Drug Resist Updat. 2016; 24:55-69.

30. Vinci M, Box C, Zimmermann M, Eccles SA. Tumor spheroid-based migration assays for evaluation of therapeutic agents. Methods Mol Biol. 2013; 986:253-66.

31. Zimmermann M, Box C, Eccles SA. Two-dimensional vs. three-dimensional in vitro tumor migration and invasion assays. Methods Mol Biol. 2013; 986:227-52.

32. Kessel S, Cribbes S, Bonasu S, Rice W, Qiu J, Chan LL. Real-time viability and apoptosis kinetic detection method of 3D multicellular tumor spheroids using the Celigo Image Cytometer. Cytometry A. 2017; 91:883-92.

33. Yemelyanova A, Vang R, Kshirsagar M, Lu D, Marks MA, Shih IM, Kurman RJ. Immunohistochemical staining patterns of p53 can serve as a surrogate marker for TP53 mutations in ovarian carcinoma: an immunohistochemical and nucleotide sequencing analysis. Mod Pathol. 2011; 24:1248-53.

34. Wasylishen AR, Lozano G. Attenuating the p53 Pathway in Human Cancers: Many Means to the Same End. Cold Spring Harb Perspect Med. 2016; 6:a026211.

35. Bell D, Berchuck A, Birrer M, Chien J, Cramer DW, Dao F, Dhir R, DiSaia P, Gabra H, Glenn P, Godwin AK, Gross J, Hartmann L, et al, and Cancer Genome Atlas Research Network. Integrated genomic analyses of ovarian carcinoma. Nature. 2011; 474:609-15.

36. Kurman RJ, Shih IM. Pathogenesis of ovarian cancer: lessons from morphology and molecular biology and their clinical implications. Int J Gynecol Pathol. 2008; 27:151-60.

37. Köbel M, Kalloger SE, Carrick J, Huntsman D, Asad H, Oliva E, Ewanowich CA, Soslow RA, Gilks CB. A limited panel of immunomarkers can reliably distinguish between clear cell and high-grade serous carcinoma of the ovary. Am J Surg Pathol. 2009; 33:14-21.

38. Beaufort CM, Helmijr JC, Piskorz AM, Hoogstraat M, Ruigrok-Ritstier K, Besselink N, Murtaza M, van IJcken WF, Heine AA, Smid M, Koudijs MJ, Brenton JD, Berns EM, Helleman J. Ovarian cancer cell line panel (OCCP): clinical importance of in vitro morphological subtypes. PLoS One. 2014; 9:e103988. 
39. Lawrenson K, Benjamin E, Turmaine M, Jacobs I, Gayther $\mathrm{S}$, Dafou D. In vitro three-dimensional modelling of human ovarian surface epithelial cells. Cell Prolif. 2009; 42:385-93.

40. Tothill RW, Tinker AV, George J, Brown R, Fox SB, Lade S, Johnson DS, Trivett MK, Etemadmoghadam D, Locandro B, Traficante N, Fereday S, Hung JA, et al, and Australian Ovarian Cancer Study Group. Novel molecular subtypes of serous and endometrioid ovarian cancer linked to clinical outcome. Clin Cancer Res. 2008; 14:5198-208.

41. Tan TZ, Miow QH, Miki Y, Noda T, Mori S, Huang RY, Thiery JP. Epithelial-mesenchymal transition spectrum quantification and its efficacy in deciphering survival and drug responses of cancer patients. EMBO Mol Med. 2014; 6:1279-93.

42. Paullin T, Powell C, Menzie C, Hill R, Cheng F, Martyniuk CJ, Westerheide SD. Spheroid growth in ovarian cancer alters transcriptome responses for stress pathways and epigenetic responses. PLoS One. 2017; 12:e0182930.

43. Langdon SP, Lawrie SS, Hay FG, Hawkes MM, McDonald A, Hayward IP, Schol DJ, Hilgers J, Leonard RC, Smyth JF. Characterization and properties of nine human ovarian adenocarcinoma cell lines. Cancer Res. 1988; 48:6166-72.

44. Köbel M, Piskorz AM, Lee S, Lui S, LePage C, Marass F, Rosenfeld N, Mes Masson AM, Brenton JD. Optimized p53 immunohistochemistry is an accurate predictor ofTP53mutation in ovarian carcinoma. J Pathol Clin Res. 2016; 2:247-58.

45. Cole AJ, Dwight T, Gill AJ, Dickson KA, Zhu Y, Clarkson A, Gard GB, Maidens J, Valmadre S, Clifton-Bligh R, Marsh DJ. Assessing mutant p53 in primary high-grade serous ovarian cancer using immunohistochemistry and massively parallel sequencing. Sci Rep. 2016; 6:26191. 